\title{
What is the ideal replacement for the scapholunate ligament in a chronic dissociation?
}

\author{
EJ Harvey $\mathrm{MD}^{1}$, D Hanel $\mathrm{MD}^{2}$ \\ ${ }^{1}$ McGill University, Montreal, Quebec; ${ }^{2}$ Harborview Medical Center, Seattle, Washington, USA
}

\section{EJ Harvey, D Hanel. What is the ideal replacement for the scapholunate ligament in a chronic dissociation? Can J Plast Surg 2000;8(4):143-146.}

An ideal replacement for the scapholunate ligament has not been found. The carpometacarpal bone-ligament-bone complex at the base of the third metacarpal can be used as a replacement for the scapholunate ligament. A cadaveric study of matched scapholunate ligament and third metacarpal-capitate was carried out. Data for stiffness and strength were obtained from fresh frozen specimens tested to failure with a hydraulic distractor. The third metacarpal-scaphoid ligament most closely approximated the stiffness and the strength of the scapholunate ligament. Operative replacement of the scapholunate ligament with the third metacarpal-scaphoid replacement was accomplished. Clinically, the performance of the operation is facile and, in the present study, was not associated with increased morbidity or duration of surgery compared with other options.

This study indicates that the third carpometacarpal ligament approximates the mechanical properties of the scapholunate ligament and is a good alternative for replacement surgery.

Key Words: Autograft; Biomechanics; Cadaveric study; Scapholunate ligament; Wrist instability

\section{Substitut idéal du ligament scapho-semi-lunaire dans la séparation chronique}

RÉSUMÉ : On n'a pas encore trouvé le substitut idéal du ligament scapho-semi-lunaire. Le complexe carpo-métacarpien os-ligament-os à la base du troisième métacarpien peut remplacer le ligament scapho-semi-lunaire. Il y a d'abord eu étude sur cadavres de ligaments scapho-semi-lunaires et de troisièmes ligaments capité-métacarpiens appariés. Des données ont été recueillies sur la force et la rigidité à partir de prélèvements frais congelés soumis à des tests de rupture à l'aide d'un appareil hydraulique. La force et la rigidité du troisième ligament métacarpien-scaphoïde se rapprochent sensiblement de celles du ligament scapho-semi-lunaire. On a procédé ensuite au remplacement chirurgical du ligament scapho-semi-lunaire par le troisième ligament métacarpien-scaphoïde. L'intervention a été facile à réaliser sur le plan clinique et elle n'a pas été associée, dans la présente étude, à une augmentation de la morbidité ou de la durée de l'intervention comparativement aux autres options thérapeutiques.

L'étude indique que le troisième ligament carpo-métacarpien possède des propriétés mécaniques qui se rapprochent sensiblement de celles du ligament scapho-semi-lunaire et qu'il constitue une option chirurgicale valable.

$\mathrm{S}$ capholunate dissociation is arguably the most common form of carpal instability (1-7). Rotatory subluxation of the scaphoid eventually produces well documented degenerative changes in the wrist $(2,3,5)$. Treatment for the acute dissocation is aimed at regaining the normal anatomy through either maintenance of reduction in a cast, or anatomical reduction and repair of the ligamentous relationships by surgery $(3,8,9)$. Acute dissociations are difficult to repair and seldom give an excellent functional result. The treatment of chronic dissociation is even more controversial.

One of the most common surgical options for the chronic dissociation, at this time, is intercarpal fusion $(1,4,5,10)$; this is an option that is far from ideal. Patients have decreased range of motion and strength ratings. Fusion does not restore normal wrist kinematics and eventually leads to wrist arthrosis $(3,11)$. If there are no degenerative changes in the carpal bones, the optimum treatment would be restoration of the scapholunate ligament (SLL). Use of the flexor carpi radialis or the extensor carpi radialis brevis has been described for ligament reconstruction of the SLL $(8,12)$. Other treatment options include, but are not limited to, primary repair of the ligament with possible addition of reinforcing autologous tissue, proximal row carpectomy, dorsal capsulodesis, scapholunate allograft (hemiscaphoid and lunate transplant) (1), dorsal pe- 


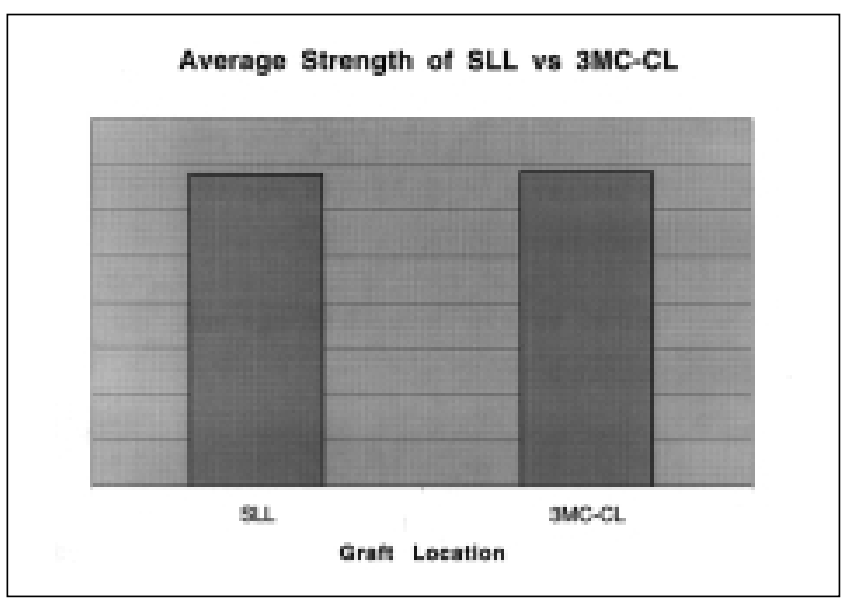

Figure 1) Strength (load to failure) of the autografts compared with that of the scapholunate ligament (SLL). 3MC-CL Third metacarpalcapitate ligament

riosteum from the radius near the tubercle and ligament replacement from the foot (13-15).

Tendon substitution for the SLL and autologous or cadaveric tendon graft augmentation are difficult. Balancing of the tendon length and maintenance of the bony anatomy are very demanding. Capsulodesis has been successful in some centres $(15,16)$. Retinacular replacement of the SLL $(14,17)$ has had some clinical success. This replacement was recently tested biomechanically and was found to be significantly weaker than the SLL it replaced (18). Ligament replacements from the foot necessitate two surgical approaches, with the added morbidity of a lower extremity wound (13).

Carpometacarpal ligaments are potentially a better option for the replacement of the scapholunate articulation. The articulation at the third metacarpal region can be sacrificed with little detriment to the patient because of the relative immobility of the metacarpals at this level. Patients undergoing this procedure have had no subsequent symptoms or subluxation at this joint. The entire procedure can be accomplished through one incision, thus avoiding any comorbidity with procedures on the feet or other areas of the body.

This study evaluates bone-ligament-bone complexes from the hand to determine a suitable biomechanical replacement for the SLL.

\section{MATERIALS AND METHODS}

Seven anatomical dissections were carried out in normal wrist cadaver sections. The wrists were approached through a dorsal flap. The carpometacarpal articulations, scapholunate joint and distal radius were visualized.

Osteotomes and scalpel were used for harvesting the carpometacarpal ligament and SLL. The SLL was compared with the third metacarpal-capitate ligament (3MC-CL). The dorsal ligaments were the only interosseous structures tested for the 3MC-CL. The SLL was left intact, both volar and dorsal, because the substitute would need to replace the entire SLL with a dorsal ligament only. This best represents the clinical scenario where only a portion of the carpometacarpal

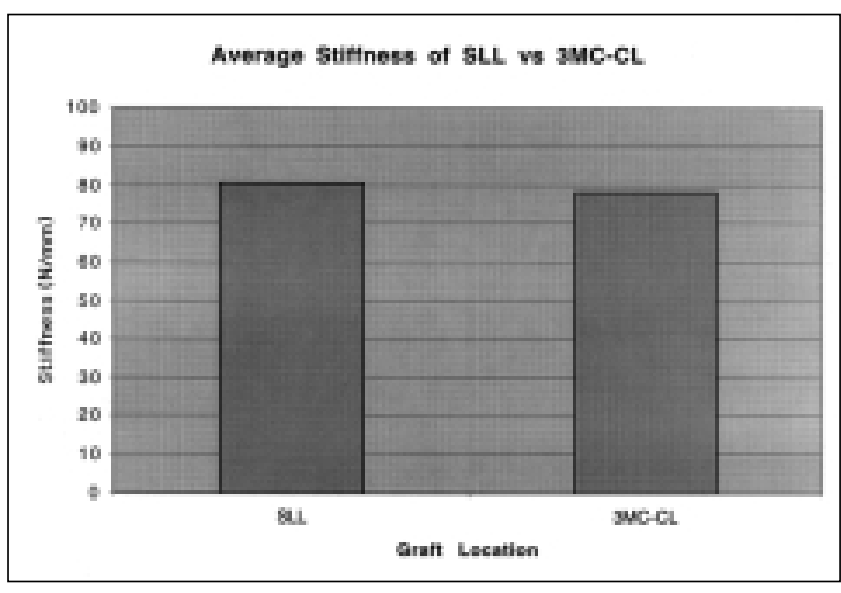

Figure 2) Stiffness of the autografts compared with that of the scapholunate ligament (SLL). 3MC-CL Third metacarpal-capitate ligament

joint would be harvested as autograft to retain joint stability at the donor site. The ligaments were matched in width to the SLL for that cadaver hand.

Custom potting devices were constructed for holding the bone-ligament-bone complexes during testing. The ligaments were kept moist and did not desiccate during the testing process. The ligament was tested to failure uniaxially at $10 \mathrm{~mm} / \mathrm{min}(0.17 \mathrm{~mm} / \mathrm{s})$ on an Instron materials testing machine (Instron Inc, United States). This is a standard testing mode for ligament failure that allows comparison with other biomechanical studies.

Failure force versus displacement curves were obtained. Ligament load to failure (Figure 1) and stiffness (Figure 2) were calculated from these curves. The load to failure (strength) values were quantitated in Newtons and the stiffness in N/m. These were then normalized to represent a percentage of the SLL for that group of ligaments from each cadaveric wrist. This allowed comparison between the different wrists. Kruskal-Willis rank testing was used to compare each ligament set with the overall scapholunate group for both stiffness and failure load.

Clinically, the operative procedures were evaluated to see whether any unexpected events occurred (infection, loss of reduction, difficulty with performance of procedure, pain at donor site, subluxation at donor site joint space and increase in operative time compared with dorsal periosteal retinacular graft).

\section{RESULTS}

The average strength or failure load of the SLL was $170.24 \mathrm{~N}$ (SD 97). The average strength of the 3MC-CL was $171.63 \mathrm{~N}$ (SD 61). Normalized as a percentage of the SLL strength, the average values for the 3MC-CL and SLL were $101 \mathrm{~N}$ and $100 \mathrm{~N}$, respectively. The 3MC-CL was not significantly different from the SLL $(\mathrm{P}=0.825)$. The normalized comparison of the average failure load is shown in Figure 1. The 3MC-CL ranges from $50 \%$ to $340 \%$ of the SLL. This ligament is stronger than the SLL in four of seven wrists and weaker in three of seven wrists.

The average stiffness of the SLL was $80.73 \mathrm{~N} / \mathrm{mm}$ 

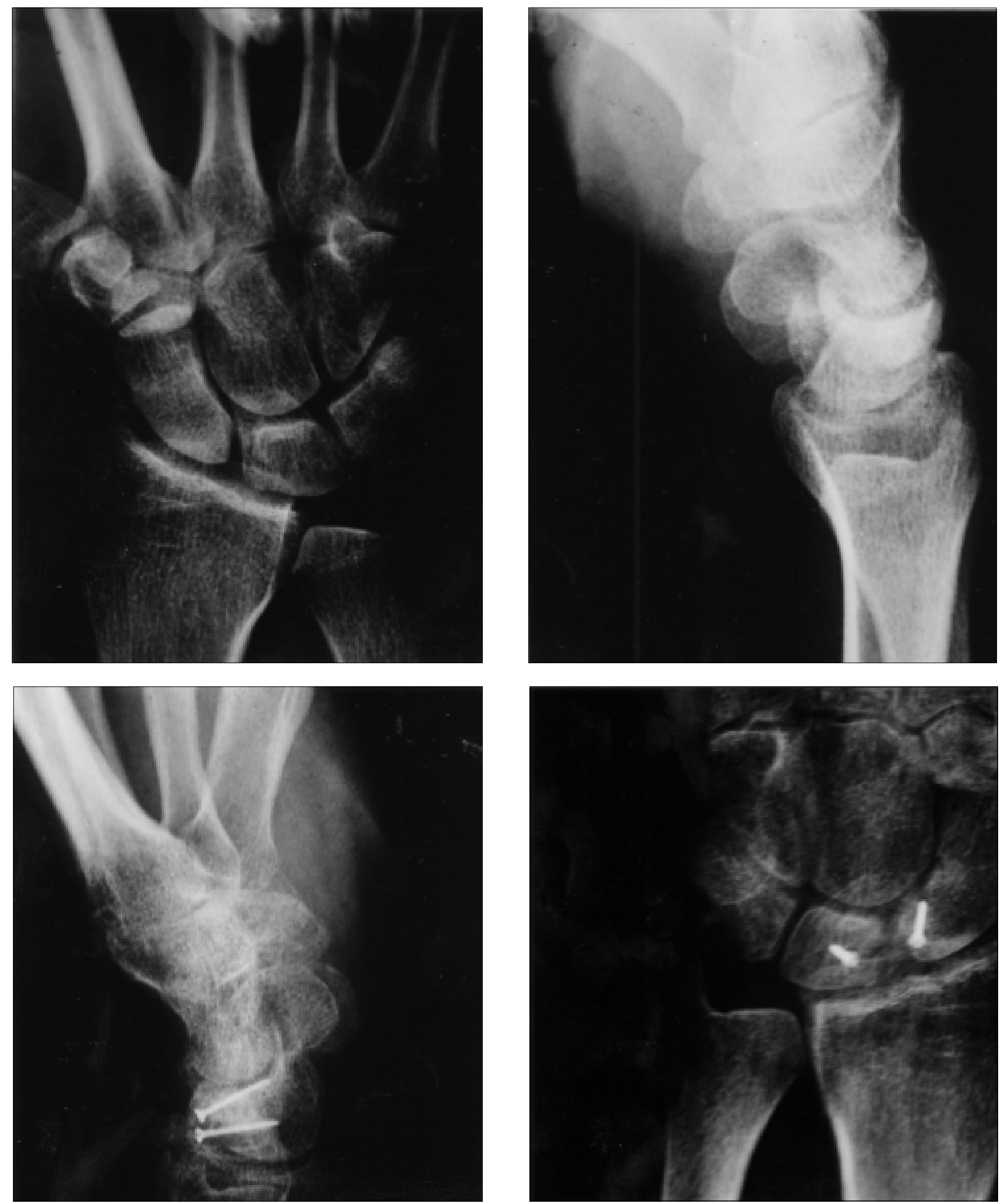

Figure 3) Top left and right Preoperative radiographs of a patient with a painful wrist and insufficiency of the scapholunate ligament. The scapholunate gap is $3.5 \mathrm{~mm}$. The scapholunate angle is aproximately $85^{\circ}$. The patient was unable to flex the palmar wrist more than $20^{\circ}$ without volar-radial pain and was unable to play sports even with a splint. Bottom left and right Postoperative radiographs of the patient with third metacarpal-capitate ligament replacement of the scapholunate ligament. Titanium $1.5 \mathrm{~mm}$ screws hold the graft in place. The patient no longer has volar abutment pain with wrist flexion. The scapholunate gap is now $2 \mathrm{~mm}$. The scapholunate angle is now $60^{\circ}$. The patient has returned to competitive sports 
(SD 59.7). The average stiffness of the 3MC-CL was $78.4 \mathrm{~N} / \mathrm{mm}$ (SD 21). Normalized as a percentage of the SLL stiffness, the average values for the 3MC-CL and SLL were $97 \mathrm{~N}$ and $100 \mathrm{~N}$, respectively. The 3MC-CL were not significantly different from the SLL $(\mathrm{P}=0.541)$. The SLL was stiffer than the 3MC-CL in only three of seven wrists.

The cadaveric feasibility study revealed that harvesting the graft was easy. Clinically, the operation was facile with live subjects. The donor graft was harvested through the same incision as the approach to the SLL. Radial cancellous bone was used to fuse the 3MC-CL joint. This was obtained through the same approach. Patients were placed in a cast for six weeks and then allowed full range of motion of the wrist. $\mathrm{K}$-wires were removed at the same time as the cast was removed. Small titanium screws were used during the operation to hold the graft in an anatomical position, and these were left in place (Figure 3).

\section{DISCUSSION}

A wrist with scapholunate dissociation is prone to developing arthrosis $(2,3,5)$. Treatment of the degenerative wrist is difficult. There are options for late reconstruction, but few of these options restore normal anatomy or function $(2,4,5,8-12)$. Theoretically, a bone-ligament-bone replacement would allow restoration of an anatomically correct and functioning wrist without sacrificing motion, strength or function. This study compared the mechanical properties of three potential replacements with those of the SLL.

The SLL was not significantly different from the 3MC-CL for strength $(\mathrm{P}=0.825)$ or stiffness $(\mathrm{P}=0.767)$. The ultimate load values in this study $(170 \pm 97 \mathrm{~N}$ at $0.17 \mathrm{~mm} / \mathrm{s}$ for SLL) were comparable with other values in the literature. Failure loads of $232 \mathrm{~N}$ at $1.7 \mathrm{~mm} / \mathrm{s}$ were reported by Pin et al (19) and $260 \pm 73 \mathrm{~N}$ at $0.1 \mathrm{~mm} / \mathrm{s}$ by Svoboda et al (13) for the SLL. Stiffness values for the SLL in this study were $81 \pm 60 \mathrm{~N} / \mathrm{mm}$ compared with $150 \pm 46 \mathrm{~N} / \mathrm{mm}$ reported by Svoboda et al (13).

The actual benefit of having a replacement that is matched to the SLL is not proven. An autograft that approximates the strength and stiffness of the SLL is desirable, however. The use of a hand-based autograft with mechanical properties similar to those of the SLL would have the same theoretical advantages as the patellar ligament replacement for the anterior cruciate ligament.

The data in this study suggest that the periosteal retinacular replacement of the SLL as described by Weiss (17) may not be biomechanically sound as a replacement for the SLL. The dorsal periosteal ligament is significantly weaker and less stiff than the SLL. Svoboda et al (13) compared autografts from the foot with the SLL. The dorsal metatarsal ligament of the fourth and fifth metatarsals, a dorsal tarsometatarsal ligament and the dorsal calcaneocuboid ligament were all significantly weaker than the SLL. The SLL was significantly stiffer than all their autografts except for the tarsometatarsal ligament. There was no adequate autograft from the foot for SLL replacement. Ligament replacement from the foot also necessitates two surgical approaches with the added morbidity of a lower extremity wound.

This study indicates that, of the bone-ligament-bone complexes from the hand that were tested, the $3 \mathrm{MC}-\mathrm{CL}$ is similar to the SLL in strength and stiffness. This autograft is a biomechanically viable replacement for the SLL. The initial clinical data suggest that the theoretical biomechanical advantage might have real world application for scapholunate replacement.

\section{REFERENCES}

1. Coe M, Spitellie P, Trumble TE, Tencer AF, Kiser P. The scapholunate allograft: A biomechanical feasibility study. J Hand Surg [Am] 1995;20:590-6.

2. Ashmead D IV, Watson HK, Damon C, Herber S, Paly W. Scapholunate advanced collapse wrist salvage. J Hand Surg [Am] 1994;19:741-50.

3. Dobyns J, Linscheid F, Chao E, Weber E, Swanson G. Traumatic instability of the wrist. Inst Course Lect 1975;24:182-99.

4. Kleinman WB, Carroll C IV. Scapho-trapezio-trapezoid arthrodesis for treatment of chronic static and dynamic scapho-lunate instability: A 10-year perspective on pitfalls and complications. J Hand Surg [Am] 1990;15:408-14.

5. Krakauer JD, Bishop AT, Cooney WP. Surgical treatment of scapholunate advanced collapse. J Hand Surg [Am] 1994;19:751-9.

6. Linscheid RL. Scapholunate ligamentous instabilities (dissociations, subdislocations, dislocation). Ann Chir Main 1984;3:323-30.

7. Mayfield JK. Wrist ligamentous anatomy and pathogenesis of carpal instability. Orthop Clin North Am 1984;15:209-16.

8. Minami A, Kaneda K. Repair and/or reconstruction of scapholunate interosseous ligament in lunate and perilunate dislocations. J Hand Surg [Am] 1993;18:1099-106.

9. Palmer AK, Dobyns JH, Linscheid RL. Management of post-traumatic instability of the wrist secondary to ligament rupture. J Hand Surg [Am] 1978;3:507-32.

10. Watson HK, Hempton RF. Limited wrist arthrodeses. I. The triscaphoid joint. J Hand Surg [Am] 1980;5:320-7.

11. Viegeas SF, Patterson RM, Peterson PD, et al. Evaluation of the biomechanical efficacy of limited intercarpal fusions for the treatment of scapho-lunate dissociation. J Hand Surg [Am] 1990;15:120-8.

12. Augsburger S, Necking L, Horton J, Bach AW, Tencer AF. A comparison of scaphoid-trapezium-trapezoid fusion and four-bone tendon weave for scapholunate dissociation. J Hand Surg [Am] 1992;17:360-9.

13. Svoboda SJ, Eglseder WA Jr, Belkoff SM. Autografts from the foot for reconstruction of the scapholunate interosseous ligament. J Hand Surg [Am] 1995;20;980-5.

14. Weiss A-P. Scapholunate ligament reconstruction using a bone-retinaculum-bone autograft: A new technique. Am Acad Orthop Surg Transcripts 1996;213:169.

15. Wintman BI, Gelberman RH, Katz JN. Dynamic scapholunate instability: Results of operative treatment with dorsal capsulodesis. J Hand Surg [Am] 1995;20:971-9.

16. Blatt G. Capsulodesis in reconstructive hand surgery. Dorsal capsulodesis for the unstable scaphoid and volar capsulodesis following excision of the distal ulna. Hand Clin 1987;3:81-102.

17. Weiss AP. Scapholunate ligament reconstruction using a bone-retinaculum-bone autograft. J Hand Surg [Am] 1998;23:205-15.

18. Shin SS, Moore DC, McGovern RD, Weiss AP. Scapholunate ligament reconstruction using a bone-retinaculum-bone autograft: A biomechanic and histologic study. J Hand Surg [Am] 1998;23:216-21.

19. Pin PG, Nowak M, Logan SE, Young VL, Gilula LA, Weeks PM. Coincident rupture of the scapholunate and lunotriquetral ligaments without perilunate dislocation: Pathomechanics and management. J Hand Surg [Am] 1990;15:110-9. 